\title{
Representasi Makna Iklan Mi Lemonilo Tahun 2020 Episode "Mie Hebat Untuk Keluarga Sehat" (Analisis Semiotik Charles Morris)
}

\author{
Nur Mahmudah El Madja \\ Program Studi Magister Media Komunikasi, Universitas Airlangga \\ Jl. Mayjen. Prof. Dr. Moestopo 47, Surabaya \\ E-mail: nurmahmudahelmadja@yahoo.com
}

Received: June 2021; Accepted: October 2021; Published: December 2021

\begin{abstract}
Abstrak
Iklan pada dasarnya bertujuan untuk memengaruhi masyarakat. Dalam prosesnya, iklan dapat bersifat informatif atau manipulatif. iklan juga bertujuan memberikan gambaran kepada konsumen agar konsumen tertarik kepada produk yang di iklankan. Perbedaan sifat tersebut tergantung pada upaya dalam mencapai tiga tujuan komunikasi massa dalam periklanan yaitu tujuan kognitif, afektif, dan psikomotorik. Iklan Mi Lemonilo berisikan informasi verbal dan visual yang bertujuan promosi bahwa mi tersebut sehat. Penelitian ini bersifat deskriptif kualitatif dengan menggunakan analisis semiotik model Charles Morris dimana hasil penelitian tersebut akan mengetahui bentuk semantic, sintaksis, dan pragmatik dari iklan Mi Lmonilo tahun 2020 episode "Mie Hebat Untuk Keluarga Sehat". Bentuk semantik guna mengetahui hubungan tanda dengan maksud disampaikan sebenarnya. Bentuk pragmatik guna mengetahui hubungan dengan penggunaan tanda dan akibatnya dalam satu tingkah lagu yang nyata. Sedangkan, bentuk sintaksis berhubungan dengan tata cara Menyusun tanda secara bersama untuk membentuk satu gabungan tanda yang bisa berupa kata, frasa, kalimat, dan pikiran utuh suatu teks atau konteks.
\end{abstract}

Kata Kunci : Iklan, Mi Lemonilo, Semiotik, Charles Morris.

\section{PENDAHULUAN}

Perkembangan kegiatan perekonomian menyebabkan beragam produk baru bersaing. Persaingan ketat tersebut membuat produsen semakin berlomba merebut perhatian konsumen. Berdasarkan sudut pandang konsumen, banyaknya pilihan produk membuat variasi konsumsi semakin memenuhi kebutuhannya, lain sisi justru membuat konsumen semakin bingung menentukan produk mana yang baik bagi dirinya. Hal ini peran iklan sangat dibutuhkan untuk memenangkan persaingan menarik konsumen.

Menurut Data Nielsen Advertising Intelligence (Ad Intel) total belanja iklan pada tahun 2019 sebesar Rp168 Triliun atau bertumbuh 10\% dibandingkan dengan 2018. Sementara nilai total belanja iklan tahun 2020 mencapai Rp122 triliun. Lonjakan belanja iklan terbesar terjadi sejak Juni 2020 hingga Juli 2020, yang nilainya mencapai Rp 18,3 triliun. Angka itu setara 15\% dari belanja iklan selama Januari-Juli 2020 (www.nielsen.com, 2020).

Data di atas menunjukkan bahwa iklan masih menjadi pilihan utama produsen untuk memasarkan produknya supaya dibeli dan dinikmati konsumen. Menurut Lukitaningsih (2013), iklan dapat menjadi strategi pemasaran efektif menarik konsumen untuk memenangkan persaingan dengan industri sejenis.

Menurut Badan Pusat Statistik (BPS), perubahan gaya hidup memengaruhi pola konsumsi masyarakat (Kontan.co.id, 2020). Produk mie instan kini merupakan pilihan utama konsumen selain nasi, karena sifatnya praktis dan harganya terjangkau. Menurut data World Instant Noodles Asosiation (WINA), Indonesia termasuk negara terbesar kedua dunia setelah Tiongkok dalam mengomsumsi mie instan. Konsumsi

mie instan di Indonesia tahun 2018 mencapai 12,52 miliar bungkus (porsi) (Katadata.co.id., 2019).

doi: https://doi.org/10.51544/jlmk.v5i2.1729

(C) 2021 Jurnal Lensa Mutiara Komunikasi. This is an open access article under the CC BY-SA license Website: http://e-journal.sari-mutiara.ac.id/index.php/JLMI 
Perkembangan pola pikir dan gaya hidup konsumen juga dapat memengaruhi tumbuh kembangnya produksi mie instandi Indonesia. Satu sisi mie instan merupakan produk konsumsi yang paling banyak diminati konsumen. Sisi lainnya banyak khalayak beranggapan mengonsumsi mie instan jangka panjang dapat berdampak buruk karena dinilai mengandung banyak bahan sintetis.

Fenomena tersebut menjadi peluang PT Lemonilo Indonesia Sehat atau lebih dikenal sebagai Lemonilo merupakan perusahaan FMCG (fast moving consumer goods) berbasis teknologi yang berbasis di Jakarta Barat untuk menciptakan produk Lemonilo yang diklaim sebagai mie instan alami sebagai opsi mie instan yang lebih sehat. Tahun 2017 meluncurkan produk konsumen pertamanya yaitu mie instan Lemonilo. Mie Instan Lemonilo sudah tersebar di 28 wilayah di Indonesia dengan lebih dari 60.000 POS (point of sales) (www.lemonilo.com, 2018).

Tahun 2020 dianggap momen tepat bagi Lemonilo untuk mengenalkan produknya karena bersamaan dengan masa Pandemi Covid-19. Seperti diketahui, masa Pandemi Covid-19 membuat masyarakat untuk menekankan hidup sehat dalam mengonsumsi makanan agar tidak mudah terserang virus Covid-19. Momen ini dimanfaatkan Lemonilo gencar mengiklankan produknya. Iklan mie instan Lemonilo kerap hadir di media televisi yang disisipkan didalam cerita sinetron. Salah satu iklan Lemenilo yang kerap muncul adalah iklan yang diperankan The Baldys Family dengan tema iklan "Mie Hebat Untuk Keluarga Sehat". The Baldys Family bahkan ditunjuk sebagai Brand Ambassador Lemonilo (JPNN.com, 2020).

Kolaborasi The Baldys Family dan produk Lemonilo yang dilakukan PT Lemonilo Indonesia Sehat bertujuan ingin menarik perhatian khalayak lebih banyak. Brand image yang ingin dibangun di benak khalayak adalah The Baldys merupakan ikon keluarga yang kompak dan menjalani pola hidup sehat disejalankan dengan visi Lemonilo bahwa menciptakan produk mie instan yang sehat. Oleh karena itu, The Baldys merupakan rekanan yang tepat untuk menyampaikan gagasan produknya mengenai pentingnya hidup sehat (JPNN.com, 2020).

Iklan kolaborasi image keluarga The Baldys dengan konsep mie instan sehat merupakan strategi pemasaran yang dilakukan Lemonilo untuk menarik minat konsumen. Ini memberikan gambaran bahwa secara komunikasi, iklan Lemonilo episode "Mie Hebat Untuk Keluarga Sehat" berusaha memberikan informasi, meyakinkan atau membujuk orang banyak melalui bahasa dan disertai gambar ilustrasi agar calon konsumen menyukai, memilih, dan kemudian membeli barang yang sedang diiklankan. Menurut Wright (dikutip dalam Liliweri, 2001) iklan dapat menjadikan alat komunikasi pemasaran yang persuasif sehingga dapat mengajak bahkan membujuk khalayak untuk membeli atau menggunakan suatu produk mengikuti ajakan pengiklan.

Periklanan adalah sebuah upaya pemasaran untuk menarik perhatian masyarakat terhadap suatu konten yang memuat informasi mengenai suatu hal. Dalam tataran masyarakat modern, periklanan memiliki kedudukan penting sebagai pembentuk budaya, sosial, hingga tingkat kesehatan masyarakat (Berger, 2013). Efektivitas periklanan seringkali dimanfaatkan untuk menyampaikan informasi yang bersifat manipulatif, yang secara nyata memang ditujukan untuk memanipulasi masyarakat melalui dua cara, yaitu pertama, dengan menciptakan kecenderungan untuk melakukan konsumsi sehingga masyarakat terdorong menjadi konsumen. Kedua, membantu mengarahkan keputusan konsumen dalam memilih produk dan merek (Phillips, 1997).

Komentar yang dihimpun dari www.id.quora.com memberikan hasil yang beragam mengenai iklan konsep mie instan sehat. Sukma Apriliyani berkomentar "Kalau dikatakan lebih 
sehat dari mie instan lain mungkin ya karena jumlah kalori yang lebih sedikit dan proses pembuatan mie yang lebih lama/berbeda dari mie instan lain". Harry S. Nugraha berkomentar "Lemonilo ini hanyalah produk instan dari pabrik yang menggunakan 'kesehatan' sebagai nilai jual dan slogan marketingnya" (id.quora.com, 2020).

Pendekatan model semiotik Morris tepat digunakan untuk menjawab permasalahan di atas. Pendekatan model semiotik Morris relevan digunakan dalam analisis teks berita dan iklan (Chafidzoh, 2020; Irmayanti, 2014). Alasan lain pendekatan model semiotik Morris digunakan karena jarang digunakan oleh peneliti terhadap iklan mie instan. Penelitian Haryono dan Putra (2017) menerapkan model semiotik Roland Barthes dalam iklan Aqua Versi "Temukan Indonesiamu". Penelitian Chafidzoh (2020) menerapkan model semiotik Morris pada iklan Mobil "FORD" di Koran Arab Digital.

Berdasarkan urian di atas maka penelitian ini ingin. Representasi Makna Iklan Mi Lemonilo Tahun 2020 Episode "Mie Hebat Untuk Keluarga Sehat" melalui pendekatan semiotik Charles Morris.

\section{TINJAUAN LITERATUR}

\section{Iklan sebagai Media Komunikasi}

Iklan adalah kegiatan menjual barang dan/atau jasa kepada masyarakat (Chafidzoh, 2020). Iklan dimanfaatkan bertujuan untuk memengaruhi atau mengajak orang lain sesuai arahan pengiklan (Lukitaningsih, 2013). Menurut Wright (dikutip dalam Liliweri, 2001) iklan dapat menjadikan alat komunikasi pemasaran yang persuasif sehingga dapat mengajak bahkan membujuk khalayak untuk membeli atau menggunakan suatu produk mengikuti ajakan pengiklan.

Komunikasi merupakan proses penyapaian informasi dengan tujuan memahami pesan yang disampaikan (Suprapto, 2009). Salah satu jenis komunikasi adalah komunikasi massa, yang dimaknai komunikasi yang dilaksanakan kepada kelompok besar penerima pesan (massa) dengan menggunakan media yang mampu memfasilitasi proses dan tujuan penyampaian pesan yang diinginkan (Daryanto, 2014).

Terdapat beragam fungsi dari komunikasi massa, antara lain sebagai penyedia informasi, pengawasan terhadap lingkungan, bimbingan, transmisi budaya, hiburan, dan fungsi persuasif. Fungsi terakhir dari komunikasi massa tersebut, yaitu persuasif, merupakan salah satu faktor utama dari aplikasi komunikasi massa dalam ranah bisnis. Fungsi persuasif dari komunikasi massa adalah untuk mempengaruhi pemikiran masyarakat berdasarkan pesan atau informasi yang disampaikan menggunakan media massa. Isi dari media massa yang dikemas dalam bentuk artikel, editorial, komentar, maupun periklanan mampu membangun opini dan program dalam pemikiran masyarakat. Secara tanpa sadar, maka masyarakat akan terpengaruh atau termotivasi untuk mengambil sikap sesuai opini yang terbangun dan melaksanakan program sesuai dengan apa yang disampaikan dalam media (Sharma, 2018).

Fungsi persuasif dari komunikasi massa yang dikaji dalam tulisan ini adalah yang dikemas dalam bentuk periklanan. Sebagaimana diketahui, bahwa periklanan adalah sebuah upaya pemasaran untuk menarik perhatian masyarakat terhadap suatu konten yang memuat informasi mengenai suatu hal. Dalam tataran masyarakat modern, periklanan memiliki kedudukan penting sebagai pembentuk budaya, sosial, hingga tingkat kesehatan masyarakat (Berger, 2013). Efektivitas periklanan seringkali dimanfaatkan untuk menyampaikan informasi yang bersifat manipulatif, yang secara nyata memang ditujukan untuk memanipulasi masyarakat melalui dua cara, yaitu pertama, dengan menciptakan kecenderungan untuk melakukan konsumsi 
sehingga masyarakat terdorong menjadi konsumen. Kedua, membantu mengarahkan keputusan konsumen dalam memilih produk dan merek (Phillips, 1997).

Secara garis besar terdapat dua karakteristik informasi yang dimuat dalam periklanan, yaitu yang bersifat informatif dan manipulatif. Keduanya jelas mengarah pada tujuan persuasif namun dengan pendekatan yang berbeda. Setiap iklan pada dasarnya memuat informasi mengenai suatu produk, merek, atau hal apapun yang ingin diiklankan. Iklan yang informatif berupaya untuk mempengaruhi masyarakat agar melakukan pembelian dan konsumsi dengan cara menyajikan informasi yang disusun sedemikian rupa hingga terlihat menarik (Phillips, 1997).

Tujuan dari setiap iklan adalah untuk mempengaruhi masyarakat (persuasif), sehingga dalam proses penyampaian informasi yang dimuat dalam iklan membutuhkan penerapan komunikasi massa yang efektif. Komunikasi massa memegang peranan penting dalam menyampaikan informasi, membujuk, mengingatkan, dan mendorong terbentuknya sikap dan perilaku masyarakat yang menjadi penerima informasi. Hasil yang dicapai dari penerapan komunikasi massa berupa perubahan tingkat pengetahuan dari masyarakat sesuai dengan informasi yang dimuat dalam iklan, sehingga dapat dikatakan terdapat korelasi antara iklan dan pengetahuan masyarakat (Sugandini \& Djawoto, 2018).

Efektivitas iklan dan kekuatan persuasif dari iklan dapat dipengaruhi oleh tingkat manipulasi dari informasi yang dimuat di dalamnya. Sifat manipulatif iklan dapat diukur menggunakan beberapa indikator, antara lain promosi nilai yang tidak diinginkan konsumen, mengiklankan informasi yang menyesatkan, menciptakan nilai yang tidak diterima masyarakat, dan pengaruh untuk membeli barang yang tidak dibutuhkan secara berlebihan (Rathy \& Sammy, 2015).

Tujuan-tujuan yang ingin dicapai dengan mengintegrasikan unsur tersebut pada dasarnya tetap sesuai dengan tujuan dari komunikasi massa, yaitu untuk tujuan kognitif, afektif, dan psikomotorik. Tujuan kognitif dari komunikasi adalah untuk menyampaikan informasi yang dapat mendorong peningkatan wawasan dan pengetahuan dari komunikan. Tujuan afektif dari komunikasi adalah untuk mendorong berkembangnya perasaan tertentu berdasarkan pemikiran atau ide yang disampaikan. Tujuan psikomotorik dari komunikasi adalah mendorong terjadinya perubahan pada sikap dan perilaku dari komunikan (Suprapto, 2009).

Tujuan-tujuan tersebut dapat dicapai dengan lebih mudah jika periklanan diterapkan dengan mengkombinasikan beberapa media massa sekaligus, namun dengan menghindari proses yang repetitif. Sinergi beberapa media massa untuk menyampaikan periklanan dapat menarik perhatian masyarakat secara lebih besar daripada iklan yang disampaikan dengan repetitif. Sinergi tersebut juga mampu membentuk sikap kuat terhadap hal yang diiklankan (Chang \& Thorson, 2014). Namun demikian, sinergi yang dilakukan tetap harus diupayakan agar tidak sampai membuat masyarakat merasa terganggu akibat intensitas iklan yang terlalu tinggi. Iklan yang disampaikan secara berlebih dengan memanfaatkan banyak media massa justru dapat ditafsirkan oleh masyarakat sebagai iklan yang manipulatif, yang dapat mendorong terciptanya respon negatif (Fachryto \& Achyar, 2018).

Berdasarkan beberapa pendapat di atas maka iklan pada dasarnya bertujuan untuk mempengaruhi masyarakat. Dalam prosesnya, iklan dapat bersifat informatif atau manipulatif. Perbedaan sifat tersebut tergantung pada upaya dalam mencapai tiga tujuan komunikasi massa dalam periklanan, yaitu tujuan kognitif, afektif, dan psikomotorik. Penerapan komunikasi massa dalam iklan yang bersifat manipulatif memang mampu mendorong peningkatan efektivitas dan efisiensi iklan dalam membentuk sikap dan perilaku pada masyarakat. 


\section{Iklan dalam Kajian Semiotik}

Iklan bertujuan mengajak, mengarahkan, meyakinkan, bahkan membujuk, khalayak agar membeli produk yang diiklankan melalui unsur verbal (kebahasaan) dan unsur nonverbal (luar bahasa) seperti tampilan visual (Chafidzoh, 2020).

Pendapat di atas pada dasarnya iklan memberikan pengertian bahwa iklan dibangun melalui tanda dengan unsur verbal dan unsur nonverbal. Menurut Keraf (2010) unsur verbal tertulis dianggap lebih efesien, karena felksibel dan jangkauannya luas daripada bahasa lisan, kecuali melalui radio atau televisi. Unsur nonverbal juga lebih efektif karena dapat memberikan tampilan visual yang dapat meyakinkan khalayak (Keraf, 2010).

Tanda dalam ilmu Semiotik dapat berbentuk verbal dan nonverbal yang didalamnya berisi makna yang dapat merepresentasikan selain dirinya sehingga dapat diinterpretasikan oleh khalayak (Danesi, 2010, hal. 7). Makna tidak statis tapi bersifat dinamis (Fiske, 2012, hal. 77), sesuai dengan keadaan sosial budaya masyarakat (Haryono \& Putra, 2017).

Menurut Noth (1995), yang dikutip dalam (Abdullah, 2011), semiotika dalam periklanan menawarkan perspektif interdisiplin (ilmu ekonomi dan semiotika) dalam mempelajari pertukaran tanda dan penelitian pertukaran komoditas. Semiotik menyediakan perangkat teoretis untuk menganalisa tanda-tanda dan proses komunikasi pada iklan. Tanda-tanda yang melekat pada iklan seperti warna, suara, tipografi, pesan, hingga gestur (bahawa tubuh).

\section{Semiotik Model Charles Morris}

Charles Morris (1901-1979) menganggap semiotika sebagai dasar untuk memahami bentuk utama aktivitas manusia dan hubungan antar manusia karena tanda memediasi semua aktivitas dan hubungan manusia (Fan, 2006). Charles Morris berpendapat bahwa analisis semiotik, baik visual maupun verbal, memperlakukan semua pesan dalam suatu budaya sebagai sistem simbol yang dapat dibaca dan ditafsirkan. Contoh menganggap novel sebagai cerita tentang orang-orang dan kehidupannya, dan lukisan menawarkan penjelasan tentang penampakan sesuatu, semiotika dapat dianggap menawarkan cerita tentang membaca atau membuat pesan. Dengan kata lain, semiotika membantu menafsirkan dan menjelaskan aturan tersembunyi yang mendasari produksi tanda dan tanggapan interpretatif karena berfokus pada studi dan analisis tanda yang digunakan dalam komunikasi (Chafidzoh, 2020).

Charles Morris mengoptimalkan pemahaman tentang praktik komunikasi teknis dan memberikan poin penyelidikan yang baik. Pendekatan semiotik dalam komunikasi teknis model Morris dapat menjadi alat teoretis dan praktis yang nyata untuk membantu praktisi dan peneliti mempelajari dan menganalisis penggunaan elemen visual dan verbal dalam komunikasi teknis (Fan, 2006).

Morris membagi bidang semiotika menjadi sintaksis, semantik, dan pragmatik. Sintaksis adalah studi tentang hubungan tanda dan tanda; semantik adalah studi tentang hubungan tanda dan objek; dan pragmatik adalah studi tentang hubungan tanda dan interpreter. Trikotomi semiotika ini menyediakan sarana untuk mengeksplorasi makna tanda, struktur di antara tanda, dan respons yang ditimbulkan oleh tanda, sehingga berkontribusi pada pemahaman yang lebih baik tentang tanda sebagai sarana komunikasi (Fan, 2006). Argumen Morris untuk hubungan tak terpisahkan dari tiga komponen semiotika menekankan bahwa harus mempelajari tanda apa pun - visual atau verbal - dari ketiga dimensi semiotika karena tidak ada satu dimensi pun yang cukup dengan sendirinya untuk menjelaskan sifat penuh semiotika (Chafidzoh, 2020). 
Ben Barton dan Marthalee Barton menjelaskan model Morris dalam hal konten visual dalam Simplicity in Visual Representation: A Semiotic Approach. Sintaksis adalah studi tentang "hubungan elemen visual dalam teks satu sama lain, apakah teks itu visual tunggal, atau seluruh dokumen, tampilan komputer, atau panel kontrol"; semantik adalah studi tentang hubungan representasi visual dengan referensi, termasuk objek, konsep, dan ide; dan pragmatik adalah studi tentang hubungan representasi visual dengan kondisi produksi dan penggunaannya, termasuk karakteristik pemirsa, tujuan, dan tugas (Fan, 2006).

Secara operasional semiotik Model Charles Morris pada iklan adalah sintaktis membahas relasi elemen visual bertujuan memberikan makna semantik membahas relasi representasi visual dengan referensi, termasuk objek, konsep, dan ide yang ditandai. Istilah denotasi dan konotasi digunakan untuk menggambarkan hubungan antar kedua hal tersebut. Pragmatik membahas korelasi representasi visual dengan kondisi produksi dan penggunaannya (Chafidzoh, 2020).

\section{METODE}

Penelitian ini menggunakan pendekatan deskriptif kualitatif. Deskriptif kualitatif dalam konteks ini adalah menjelaskan atau memaparkan secara mendalam gejala, peristiwa kebahasaan baik verbal maupun visual tertentu sesuai dengan fakta kebahasaan yang ada (Chafidzoh, 2020; Creswell, 2015)

Teknik pengumpulan data dilakukan secara dokumentatif dengan data dan sumber data dari materi iklan Mi Lemonilo tahun 2020 episode "Mie Hebat Untuk Keluarga Sehat". Data diperoleh dari situs Youtube.com. Adapun jenis data dan sumber data.

a. Jenis data primer berupa video iklan Mi Lemonilo tahun 2020 episode "Mie Hebat Untuk Keluarga Sehat". Sedangkan, jenis data sekunder berupa buku, jurnal, dan situs web yang relevan.

b. Sumber data primer berupa peneliti mengamati iklan Mi Lemonilo tahun 2020 episode "Mie Hebat Untuk Keluarga Sehat" yang akan di teliti menggunakan analisis semiotik Charles Morris. Sedangkan, sumber data sekunder berupa buku, jurnal, dan situs web yang berhubungan dengan fokus penelitian, yakni Representasi Makna Iklan Mi Lemonilo Tahun 2020 Episode "Mie Hebat Untuk Keluarga Sehat" dengan menggunakan analisis semiotik Charles Morris.Penelaahan artikel sebagai sumber literatur terpilih terkait topik branding oleh pemimpin politik di media sosia dan komunikasi politik. Terakhir penulis mencari literatur review perkembangan political branding di era digital. Kemudian dalam mengolah artikel-artikel jurnal yang telah dikumpulkan, penulis menggunakan perspektif komunikasi politik dalam melakukan analisis, serta dihubungkan dengan konteks Indonesia dalam mengkorfirmasi fenomena tersebut.

Teknik analisis dalam penelitian ini menggunakan analisis semiotik model Charles Morris, yang terdiri dari trikotomi elemen sintaksis, semantik, dan pragmatik dengan tujuan medeskripsikan serta mengupas makna yang terkandung dalam iklan Mi Lemonilo tahun 2020 episode "Mie Hebat Untuk Keluarga Sehat". Langkah-langkah analisis yang dilakukan adalah:

a. Mengumpulkan data dengan metode simak catat dengan melihat dan mempelajari verbal dan visual iklan Mi Lemonilo tahun 2020 episode "Mie Hebat Untuk Keluarga Sehat".

b. Coding, merupakan teknik memilih dan memilah data yang relevan dalam iklan Mi Lemonilo tahun 2020 episode "Mie Hebat Untuk Keluarga Sehat" dengan fakta kebahasaan yang ada. 
c. Mengklasifikasi data dalam trikotomi analisis semantik, sintaktis, dan pragmatik model semiotik Charles Morris.

d. Menarik kesimpulan.

\section{PEMBAHASAN}

Secara terminologis, semiotik adalah cabang ilmu yang berurusan dengan dengan pengkajian tanda dan segala sesuatu yang berhubungan dengan tanda, seperti sistem tanda dan proses yang berlaku bagi tanda (Sartini, 2007). Semiotik adalah salah satu cabang ilmu yang mempelajari berbagai macam objek-objek, peristiwa-peristiwa, bahkan seluruh kebudayaan sebagai tanda. Tanda yang dimaksudkan di sini adalah masih adanya maksud lain yang harus digali lebih rinci agar maksud yang ingin disampaikan dapat dengan tepat diketahui.

Charles Morris menyebutkan bahwa istilah yang berhubungan dengan ilmu isyarat yang dikemukakan merupakan definisi semiotik. Charles Morris mengatakan bahwa bahasa adalah sebuah sistem sign dibedakan atas signal dan simbol. Semiotik tidak hanya berhubungan dengan isyarat bahasa, tetapi juga berhubungan dengan isyarat-isyarat di luar bahasa dalam komunikasi antara manusia satu dengan yang lainnya (Harbi, 2019). Tanda adalah subtitusi untuk hal-hal lain. Oleh karena itu, sing memerlukan tafsiran lanjutan. Misalnya jika saya melihat air yang direbus sudah mendidih, maka sign yang dimaksudkan adalah air yang dimasak sudah matang. Charles Morris mendefinisikan semiotik sebagai ilmu tentang sign dan membedakannya menjadi tiga macam, antara lain sintaksis, semantik, dan pragmatik (Parera, 2004).

Pada pembahasan kali ini iklan Mi Lemonilo akan dianalisis menggunakan metode analisis semiotik Charles Morris. Pembahasan mengenai makna semantik, pragmatik, dan sintaksis akan dibagi perdialog antara Adik dengan Kak Naura, Adik dengan Abang, Adik dengan orang tua, narasi dari narator, dan ucapan dari semua anggota keluarga secara bersamaan. Berikut pembagian dialog dalam iklan:

Dialog 1 antara Adik dengan Kak Naura

a. Adik : "Kak Naura, main tebak cepet, yuk! Pilih praktis atau enak?"

b. Kak Naura : "Dua-duanya."

Dialog 2 antara Adik dengan Abang
a. Adik
: "Hmm... Abang, pilih enak atau sehat?"
b. Abang
: "Dua-duanya."

Dialog 3 antara Adik dengan orang tua
a. Adik
: "Papa, pilih praktis, enak, atau sehat?"
b. Mama
: "Tiga-tiganya dong."

Dialog 4 narasi dari narator

a. Hari gini makanan harus praktis, enak, dan sehat kayak Lemonilo tanpa pengawet, penguat rasa, dan pewarna buatan. Hmm... Mi Lemonilo mi hebat untuk keluarga sehat.

Dialog 5 antara ucapan dari semua anggota keluarga secara bersamaan

a.Seluruh Keluarga : "Bersama Lemonilo menuju generasi hebat." 
Tiga macam semiotik dari Charles Morris akan dianalisis satu-persatu berdasarkan sumber data penelitian yaitu iklan Mi Lemonilo.

\section{Perspektif Semantik}

Semantik yaitu studi tentang makna. Analisis semantik yang dimaksudkan oleh Charles Morris di sini adalah mencari tahu hubungan sign dengan maksud yang ingin disampaikan sebenarnya. Makna semantik dalam dialog pertama yaitu adik ingin menanyakan pendapat dari kakak perempuannya tentang makanan yang baik untuk dikonsumsi dengan mengajukan dua kata yang dirasa mewakili. Kemudian sang kakak menjawab dengan memilih dua kata yang diajukan oleh sang adik. Jawaban kakak menunjukkan bahwa makanan yang enak memang harus mengandung unsur dua kata yang diajukan.

Makna semantik dalam dialog kedua yaitu adik ingin menanyakan pendapat dari kakak lali-lakinya tentang makanan yang baik untuk dikonsumsi dengan mengajukan dua kata yang dirasa mewakili. Namun, dua kata tersebut tidak sama persis dengan kata yang diajukan pada kakak perempuannya. Ada salah satu kata yang dibedakan. Kemudian sang kakak juga menjawab dengan memilih dua kata yang diajukan oleh sang adik. Jawaban kakak menunjukkan bahwa makanan yang enak memang harus mengandung unsur dua kata yang diajukan.

Makna semantik dalam dialog ketiga yaitu adik ingin menanyakan pendapat dari orang tuanya tentang makanan yang baik untuk dikonsumsi dengan mengajukan tiga kata yang dirasa mewakili. Tiga kata yang diajukan oleh adik kepada orang tuanya adalah gabungan dari katakata yang telh diajukan kepada kakak-kakaknya sebelumnya. Dalam dialog ini, adik sebenarnya mengajukan pertanyaan kepada ayah. Namun, pertanyaan tersebut dijawab oleh ibu. Di dalam iklan dipilih yang menjawab pertanyaan ibu di sini bermakna bahwa anggota keluarga yang dominan di dapur adalah ibu. Sama halnya dengan konteks iklan yaitu tentang makanan. Jadi, ibu yang menjawab pertanyaan adik karena ibu yang dirasa paling mengerti tentang makanan yang baik untuk keluarga.

Makna semantik dalam dialog keempat yaitu narasi dari narator yang bertujuan memberikan kesimpulan terhadap makanan apa yang mengandung tiga unsur kata yang telah diajukan oleh adik yaitu, praktis, enak, dan sehat. Makanan tersebut yaitu Mi Lemonilo. Kemudian narator juga memberikan rincian atas kandungan yang terdapat dalam Mi Lemonilo yaitu tanpa pengawet, penguat rasa, dan pewarna buatan. Terakhir ditutup narator dengan mengucapkan slogan dari Mi Lemonilo yaitu Mi Lemonilo mi hebat untuk keluarga sehat.

Makna semantik dalam dialog keempat yang diucapkan seluruh anggota keluarga yaitu mengajak penonton iklan untuk mengonsumsi Mi Lemonilo yang sehat agar generasi penerus menjadi generasi yang hebat.

\section{Perspektif Sintaksis}

Sintaksis berurusan dengan hubungan kata dengan kata atau dengan satuan lain yang lebih besar. Analisis sintaksis berhubungan dengan tata cara menyusun sign secara bersama untuk membentuk satu gabungan sign yang bisa berupa kata, frasa, kalimat, dan pikiran utuh suatu teks atau konteks. Secara sintaksis, dialog pertama diuraikan menjadi dua bagian. Yaitu bagian dialog adik dan kakak perempuan. Dialog adik terdiri atas komponen; 1) Kak Naura (subjek), 2) main tebak cepat, yuk! (predikat), 3) Pilih (predikat), 4) praktis atau enak? (subjek). Dialog kakak perempuan terdapat komponen Dua-duanya (predikat).

Secara sintaksis, dialog kedua diuraikan menjadi dua bagian. Yaitu bagian dialog adik dan kakak laki-laki. Dialog adik terdiri atas komponen; 1) Abang (pelengkap), 2) pilih 
(predikat), dan 3) enak atau sehat? (subjek). Dialog kakak laki-laki terdapat komponen Duaduanya (predikat).

Secara sintaksis, dialog ketiga diuraikan menjadi dua bagian. Yaitu bagian dialog adik dan ibu. Dialog adik terdiri atas komponen; 1) Papa (pelengkap), 2) pilih (predikat), 3) praktis, enak, atau sehat? (subjek). Dialog ibu terdapat komponen Tiga-tiganya (predikat).

Secara sintaksis, dialog keempat terdiri atas komponen; 1) Hari gini (keterangan waktu), 2) makanan harus praktis, enak, dan sehat (predikat), 3) kayak Lemonilo tanpa pengawet, penguat rasa, dan pewarna buatan (keterangan), 4) Mi Lemonilo (subjek), 5) mi hebat (predikat), dan 6) untuk keluarga sehat (keterangan).

Secara sintaksis, dialog kelima terdiri atas komponen; 1) Bersama Lemonilo (predikat), dan 2) menuju generasi hebat (pelengkap).

Setelah menganalisis iklan Mi Lemonilo menggunakan teori semiotik Charles Morris, dapat diketahui bahwa tanda dari iklan tersebut adalah untuk mempromosikan dan mengajak masyarakat luas terutama yang menonton iklan tersebut untuk mengonsumsi mi yang diklaim sehat dan dapat memberikan sumbangsih untuk menciptakan generasi yang hebat. Teori semiotik Charles Morris dapat diaplikasikan dalam iklan tersebut karena pada hakikatnya bahasa mengandung sign yang perlu diberikan tafsiran agar maksud yang ingin disampaikan dapat terbaca atau dilihat oleh orang yang mendapatkan sign tersebut. Dalam konteks ini, sign disampaikan melalui sebuah iklan Mi Lemonilo.

\section{Perspektif Pragmatik}

Pragmatik yaitu analisis pengunaan dan akibat permainan kata. Analisis pragmatik berhubungan dengan pengunaan sign dan akibatnya dalam satu tingkah laku yang real.

Makna pragmatik dalam dialog pertama yaitu jawaban Kak Naura atas pertanyaan Adik tentang makanan yang diwakilkan dengan dua kata. Kak Naura dalam iklan tersebut tidak dapat memilih salah satu karena menurut kak Naura, dua kata yang digunakan Adik sebagai pilihan sama-sama penting.

Makna pragmatik dalam dialog kedua yaitu jawaban Abang atas pertanyaan adik tentang makanan yang diwakilkan dengan dua kata. Abang dalam iklan tersebut tidak dapat memilih salah satu karena menurut Abang, dua kata yang digunakan Adik sebagai pilihan sama-sama penting.

Makna pragmatik dalam diaalog ketiga yaitu jawaban Mama atas pertanyaan Adik tentang makanan yang diwakilkan dengan tiga kata. Mama dalam iklan tersebut tidak dapat memilih salah satu karena menurut Mama, tiga kata yang digunakan Adik sebagai pilihan samasama penting.

Makna pragmatik dalam dialog keempat yaitu narator ingin penonton iklan tahu bahwa mi yang praktis, enak, sehat dengan kandungan yang baik untuk tubuh adalah Mi Lemonilo. Tidak hanya itu, narator juga sebenarnya ingin mempromosikan keunggulan Mi Lemonilo yang kemudian akan mempengaruhi penonton agar mengonsumsi Mi Lemonilo.

Makna pragmatik dalam dialog kelima yaitu seluruh anggota keluarga ingin mengajak penonton iklan mengonsumsi Mi Lemonilo seperti yang dilakukan keluarga tersebut. 


\section{KESIMPULAN}

Iklan memiliki tujuan memberikan informasi dan meyakinkan orang sehingga iklan juga bersifat manipulatif. Iklan berifat manipulatif atau membujuk melalui bahasa, video, ilustrasi, dan gambar agar calon pembeli dapat menyuka dan tertarik sehingga membeli barang yang di iklankan. Pada iklan mi Lemonilo tahun 2020 episode "Mie Hebat Untuk Keluarga Sehat" tayang saat Indonesia sedang mengalami musibah adanya pandemi Covid-19 yang dimana seluruh masyarakat di Indonesia harus menjaga kesehatan dan mengatur polah makan, disini Iklan Mi Lemonilo tahun 2020 episode "Mie Hebat Untuk Keluarga Sehat" dianggap promosinya sangat tepat dengan mengiklankan mie instan sehat dan dapat di makan setiap hari.

Berdasarkan analisis semiotik model Charles Morris dari bentuk sintaksis, pragmatik, dan semantik diketahui bahwa, tanda dari iklan Mi Lemonilo yakni, mempromosikan dan mengajak masyarakat luas menonton iklan tersebut agar mengkonsumsi Mi Lemonilo yang di klaim sehat dan dapat memberikan sumbangsih untuk menciptakan generasi hebat

. Saran yang dapat disampaikan dalam jurnal ini, antara lain: (1) Perlu dilakukan kajian mengenai analisis semiotik model Charles Morris pada media karena masih sedikit peneliti menganalisis media menggunakan semiotik Charles Morris. (2) Peneliti berharap kajian semiotik Charles Morris ini lebih luas tidak hanya meneliti mengenai media seperti iklan, lagu dan novel, namun dapat menganalisis objek lain yang dianggap tepat.

\section{DAFTAR PUSTAKA}

Abdullah, F. (2011). Semiotika = Ilmu Atau Metode? Telaah Buku "Handbook od Semiotics", Winfried Noth, 1995. Dimensi, 8(2), 1-10.

Berger, A. A. (2013). Dictionary of advertising and marketing concept. USA: Left Coast Press, Inc

Chafidzoh, T. F. (2020). Representasi Visual dan Verbal Iklan Mobil "FORD” pada Koran Arab Digital (Semiotik Charles Morris). JURNAL Al-AZHAR INDONESIA SERI HUMANIORA, 5(4), 174. https://doi.org/10.36722/sh.v5i4.415

Chang, Y., \& Thorson, E. (2014). Television and web advertising synergies. Journal of advertising, 33(2), 75-84.

Creswell, J. W. (2015). Penelitian Kualitatif \& Desain Riset. Yogyakarta: Pustaka Pelajar.

Danesi, M. (2010). Pesan, Tanda, dan Makna. Yogyakarta: Jalasutra.

Daryanto. (2014). Teori komunikasi. Malang: Penerbit Gunung Samudera.

Fachryto, T., \& Achyar, A. (2018). Effect of Online Behavioral Advertising Implementation on Attitude toward Ad and Purchase Intention in Indonesian EMarketplace. Sriwijaya international journal of dynamic economics and business, 2(2), 123-138. 
Fan, J. P. (2006). Charles Morris's semiotic model and analytical studies of visual and verbal representations in technical communication. Journal of Technical Writing and Communication, 36(2), 121-139. https://doi.org/10.2190/B8XB-VY4R-R792-DQJG

Fiske, J. (2012). Pengantar Ilmu Komunikasi. Jakarta: Rajawali Pers.

Harbi, A. A. (2019). ANALISIS SEMIOTIKA CHARLES MORRIS DALAM SYAIR LAGU AYAH. 1-35.

Haryono, S. R., \& Putra, D. K. S. (2017). Identitas Budaya Indonesia: Analisis Semiotika Roland Barthes Dalam Iklan Aqua Versi "Temukan Indonesiamu." Acta Diurna, 13(2), 67-88. Diambil dari jos.unsoed.ac.id/index.php/acra_diurna/article/download/614/473 id.quora.com. (2020). Bagaimana pendapat Anda tentang iklan mie Lemonilo yang mengklaim bahwa mie tersebut aman bagi tubuh walaupun dikonsumsi setiap hari? Diambil 22 Desember 2020, dari https://id.quora.com/Bagaimana-pendapat-Andatentang-iklan-mie-Lemonilo-yang-mengklaim-bahwa-mie-tersebut-aman-bagi-tubuhwalaupun-dikonsumsi-setiap-hari

Irmayanti, M. (2014). Profesionalisme Jurnalis Media Online. Tren Pola Konsumsi Media di Indonesia, III, 797-816.

JPNN.com. (2020). Keluarga The Baldys Jadi Brand Ambassador Lemonilo. Diambil 21 Desember 2020, dari https://www.jpnn.com/news/keluarga-the-baldys-jadi-brandambassador-lemonilo

Katadata.co.id. (2019). Konsumsi Mi Instan Indonesia 2018 Turun 0,63 Persen. Diambil 21 Desember 2020, dari https://databoks.katadata.co.id/datapublish/2019/07/03/konsumsimi-instan-indonesia-turun\#

Keraf, G. (2010). Diksi dan Gaya Bahasa: Seri Retorika. Jakarta: Gramedia Pustaka Utama.

Kontan.co.id. (2020). BPS: Pola konsumsi dan gaya hidup masyarakat sudah berubah. Diambil 21 Desember 2020, dari https://nasional.kontan.co.id/news/bps-pola-konsumsi-dan-gayahidup-masyarakat-sudah-berubah

Liliweri, A. (2001). Dasar-Dasar Komunikasi Periklanan. Bandung: Citra Aditya Bakti.

Lukitaningsih, A. (2013). Iklan Yang Efektif Sebagai Strategi Komunikasi Pemasaran. Jurnal Ekonomi dan Kewirausahaan, 13(2), 116-129. Diambil dari http://ejurnal.unisri.ac.id/index.php/Ekonomi/article/view/670/576

Parera, J. D. (2004). Teori Semantik. Jakarta: Erlangga.

Phillips, M. J. (1997). Ethics and manipulation in advertising: answering a flawed indcitment. Westport: Greenwood Publishing Group, Inc. 
Rathy, C., \& Sammy, A. (2015). Advertising: product information and consumer manipulation factors influenced Malaysian consumers buying attitude. International journal of business, economics, and lawa, 8(2), 1-8.

Sartini, N. W. (2007). Tinjauan Teoritik tentang Semiotik. Masyarakat, Kebudayaan dan Politik, $1-10$.

Sharma, A. (2018). Introduction to mass communication. Chhattisgarh: Evincepub Publishing.

Sugandini, D., \& Djawoto. (2018). The Influence of Advertising, Knowledge, and Attitudes towards Electricity-Saving Behavior. Review of Integrative Business and Economics Research, 7(3), 172-180.

Suprapto, T. (2009). Pengantar teori \& manajemen komunikasi. Yogyakarta: Grasindo.

www.lemonilo.com. (2018). Lemonilo Mie Turun Harga? Kok Bisa? Diambil 21 Desember 2020, dari https://www.lemonilo.com/blog/lemonilo-mie-turun-harga-kok-bisa www.nielsen.com. (2020). Belanja Iklan 2019 Ditutup Dengan Tren Positif. Diambil 21 Desember 2020, dari https://www.nielsen.com/id/id/press-releases/2020/belanja-iklan2019-ditutup-dengan-tren-positif/ 